\title{
MEDIA APPROACHING OF ARAB SATELLITE NEWS CHANNELS
}

\section{"CASE STUDY ON THE DISAPPEARANCE OF SAUDI}

\section{JOURNALIST JAMAL KHASHOGGI"}

\author{
SUZAN EL KALLINY \\ Professor of Media, Dean of Faculty of Arts - Ain Shams University, Member of the National Council for Women \\ Member of the Supreme Council for Media Regulation, Cairo, Egypt
}

\begin{abstract}
The case of the disappearance of Saudi journalist Jamal Khashoggi on October 3, 2018, following the entry of the Saudi consulate in Istanbul, Turkey, aroused the attention of the international and Arab public opinion. The Arab media differed among themselves in dealing with the event. This study is concerned with the media treatments of Arab news channels for the disappearance of Saudi journalist Jamal Khashoggi Satellite TV.

There was a great difference in the framework of dealing with the issue of the Saudi journalist among the Arab satellite news channels, by analyzing the news processing frameworks in the Arab satellite news channels.

The researcher chose to select the following Arabic satellite news channels (Al-Arabia Saudi channel - AlJazeera Qatari channel - Nile News Egyptian channel) to conduct the study.

Finally, the analysis concluded that the absolute objectivity of satellite news channels does not exist while the news is influenced by political affiliation and ownership of the channel according to the policy of the state to which the channel belongs. The channel also varies and the news treatment of the events varies according to the nature of the event itself.

KEYWORDS: Arab Satellite, Arab News Channels, Arab Media Approaching \& Case Study of Saudi Journalist
\end{abstract}

Received: Oct 18, 2018; Accepted: Nov 08, 2018; Published: Nov 09, 2018; Paper Id.: IJCMSDEC20185

\section{INTRODUCTION}

The case of the disappearance of Saudi journalist Jamal Khashoggi on October 3, 2018, after entering the Saudi consulate in Istanbul, Turkey, has aroused the attention of international and Arab public opinion, where there were different narratives of what happened to him after entering the Saudi consulate to apply for the marriage of his Turkish fiancée.

The Arab media differed among themselves in approaching the event. Therefore, this study is concerned with the media approaching of the Arab satellite news channels for the disappearance of Saudi journalist Jamal Khashoggi in these satellite channels.

\section{Subject of the Study}

It was noted during the daily follow-ups of Arab satellite news channels that there was a great difference in the framework of dealing with the issue of the Saudi journalist Jamal Khashoggi among the Arab satellite news 
channels. The stories and news stories differed from one Arab satellite to another, prompting the researcher to study how to deal with the disappearance of Saudi journalist Jamal Khashoggi.

\section{The Importance of the Study}

- Modernity of the subject and raise it in the Arab and international public opinion.

- The different media approaching frameworks among the Arab satellite channels have aroused great controversy among the Arab public about the credibility of Arab satellite channels in dealing with issues of common concern.

- Conflicting of information, news, and stories about the disappearance of the Saudi journalist, which draws attention to the extent of objectivity of these channels and sources of information.

\section{Objective of the Study}

This study aims to:

- Analysis of the approaching frameworks of the disappearance of Saudi journalist Jamal Khashoggi in the Arab satellite news channels with different affiliations and political orientations.

- Monitoring the sources of Arab satellite information in the event of the study.

- A conclusion of the factors influencing the media approaching the subject of the study.

\section{Methodology Used}

The Survey Methodology in the context of which all the news related to the Saudi journalist was surveyed in Arab satellite channels. In the framework of the survey, methodology qualitative analysis was used.

\section{Analytical Study Society}

Arabic Satellite News Channels

\section{Sample of the Study}

The following Arab satellite channels were selected:

(El Arabia Saudi Arabia Channel - Al-Jazeera Qatari channel - Nile News Egyptian channel) over the 21 days since the announcement of the disappearance of Saudi journalist Jamal Khashoggi (October 3 to October 21)

Reasons for selection are as follows:

- $\quad$ Saudi Arabia is the owner of Al Arabiya TV channel.

- Qatar is the owner of Al-Jazeera, which has a challenging position for Saudi Arabia.

- Egypt is the owner of the Nile News Channel neutral in this case.

The theory of news frames has been used in qualitative analysis to find out the approaching frameworks of the event among the three satellite channels with different affiliations and political orientations. 
First: The general characteristics of approaching the disappearance of Saudi journalist Jamal Khashoggi among the Arab satellite news channels under study:

- The news coverage of the event was dominated by the three satellite channels, which focused on the news in the various newspapers during the analysis days (Al-Arabiya - Al-Jazeera - Nile News), while Al Jazeera was characterized by two news channels and documentaries, not just news.

- Al-Arabiya and Nile News did not pay interest for news approaching of an analytical and explanatory nature to the event. Al Jazeera, through the news reports provided by analysis and interpretation, devoted only five minutes to one report.

- The media coverage of each of the three satellite channels coincided with its official position, where Al Jazeera's extreme bias against Saudi Arabia was revealed by implicit accusations at the beginning of the news coverage of the event. These charges escalated until it reached explicit accusations against Saudi Arabia of killing the Saudi journalist. While Al-Arabiya committed itself to cover the surface of the event, which lost the news in many of the news it broadcast, while the Nile News Channel was committed to total neutrality, objectivity, and balance in the presentation of the event, which was characterized by some form of information submission.

- Al-Arabiya channel relied on official Saudi sources in its coverage of the event. Al-Jazeera relied on a variety of sources among officials of the Turkish consulate, Turkish security personnel and some official sources in Turkey. Their sources were largely biased in one direction. While the Nile News Channel relied on the news of Arab and international news agencies covering the event and did not rely on any personal sources.

- Al Jazeera focused too heavily on the event, which ranked in the ranking of news bulletins and followed the investigative approach through information, interpretation, analysis, hosting of event-related sources, and specialized sources of analysis and commentary on events. While Al-Arabiya and Nile News provided only the main news items that answered the five questions (what happened, who, where, when and why).

- Al Jazeera relied on trained and qualified media cadres that provided in-depth, interrelated, multi-conferencing and interpretation, while Al Arabiya and Nile News declined.

- Nile News coverage of the event was irregular, while the news was presented on a daily, regular, continuous and updated basis on Al-Jazeera and Al-Arabiya, which only added new information from different sources.

- Al-Arabiya's news coverage was characterized by spontaneity, improvisation and conflicting information, which made it lack of news processing. Al-Jazeera coverage was characterized by persuasive and in-depth analyzes based on logical evidence. While the Nile News Channel was committed to present information from news agencies to information that was inconsistent with the response of information to its sources.

- Al-Jazeera TV coverage of the story was based on exaggeration from the first day (October 3). On the contrary, Al-Arabiya coverage was characterized by delirium while there was a balance in the display of information that characterized the Nile News Channel.

- The coverage of Al-Arabiya channel was characterized by generality and superficiality, while the coverage of Al- 
Jazeera was characterized by the personality of the event, the excitement and the dramatic narration sometimes and at other times focused on political and security sources to analyze the event, refute it, and clarify its dimensions. Thus, the coverage was looking for reasons and backgrounds, while the Nile News Channel dealt with the news as a news item that did not receive attention or news focus, providing information about the event without mentioning the reasons, dimensions, and details.

Professional Standards in Approaching the Disappearance of the Saudi Journalist in the Three News Channels

(El Arabia - Al-Jazeera -Nile News)

The expression of credibility in the media approaching of news is one of the most important professional standards that affect the follow-up of public exposure to a specific channel. The honesty of presentation and in conveying the news, objectivity, integrity, and accuracy in the information provided and away from the excitement, the news channels must monitor aspects of the professional standards.

\section{Professional Standards for Event Handling}

Al-Arabiya channel has been fallen in many mistakes and abandoned neutrality. This was clearly demonstrated by the presentation of the statement made by Turkish President Erdogan about the incident. Where he stated, "The performance of the Saudi consul was very bad in dealing with the event." Al-Arabiya channel distorted the statement by saying that President Erdogan praised the performance of the Saudi consul in Turkey in dealing with the incident.

Al-Jazeerahas also abandoned the neutrality, where it took place in many errors highlighting the views that condemn Saudi Arabia and confirms its involvement in the killing of journalist Khashoggiover other views and opinions.

Al-Jazeera also was keen to broadcast the president's statement, "Erdogan," directly with an immediate translation of the statement without interrupting the statement, which confirms the view adopted by Qatar in the indictment of Saudi Arabia.

While the Nile News Channel has ostensibly adhered to professional standards in its news coverage, by carefully assigning information to its sources. However, in most cases, this coverage is flawed because it lacks a coherent general context. The information is not coherent and appears to be separate events that it does not collect A coherent context, as well as lack of diversity, both in the sources relied upon, which led to the lack of media treatment of the Nile News Channel of inclusion and the absence of interpretative and analytical nature.

\section{Commitment of Media Coverage to Balance}

There is a sharp contrast between the three satellite news channels regarding the balance criterion. You may notice that the Al-Arabiya channel paid attention to self-defense and compromised the balance of coverage by its constant assertion that the event does not tolerate multiple views.

While Al-Jazeera did not adhere to the criterion of balance at all, this was clearly evidenced by the adoption of views that support its tendency to accuse Saudi Arabia and focused on personal sources that support distorting the image of the Kingdom. While the Nile News Channel largely adhered to the balance criterion, providing only information from news agencies to its sources. 
"Case Study on the Disappearance of Saudi

Journalist Jamal Khashoggi"

The Commitment of Media Coverage to Objectivity

The follow-up and observation showed that Al-Arabiya and Al-Jazeera channels did not adhere to objectivity in dealing with the event. Each of them volunteered sources in a biased personal manner that served their views while obscuring and marginalizing other views, especially when the event escalated from the disappearance to the killing of the Saudi journalist Khashoggi. Al-Jazeera has taken a negative position, not neutral in the direction of accusations without concrete evidence to the Kingdom of Saudi Arabia to kill Khashoggi, while Al-Arabiya took a supportive position and supportive of the government and Saudi officials. It is noted that the cultural context of the channels has been reflected heavily on the island, which relied on official Arab and foreign informal sources.

It is noted that the Nile News Channel was the most objective in presenting information only without presenting any views of the event.

\section{Commitment to the Inclusion of Media Coverage}

It is noted from the follow-up of the three channels under study that the media coverage of the event was not covered at the level of the three channels. Al-Arabiya channel provided insufficient information and focused on certain specific aspects and other concealments. Al-Jazeera also relied on undocumented and sometimes conflicting information about Khashoggi's attack inside the Saudi consulate. While the Nile News Channel was interested in the developments of the event without focusing on explaining the details or reasons and without relying on external sources. Therefore, the media coverage in the three channels did not include coverage criteria.

\section{Adhering to Professional Standards of Image}

The professional standards of the image are one of the most important criteria that television channels must adhere to in the coverage. This could be achieved by appropriate images and angles - the commitment to the dimensions of professional responsibility in the picture by avoiding arousing national and human feelings - and not exaggerating or minimizing the event - respect for human feelings - Do not explain what the image offers to a specific party.

The three channels were based primarily on the photographic and photographic images of the Saudi journalist Khashoggi, but all were made in a professional error, namely, the use of personal images of the Saudi journalist Jamal Khashoggi and the repetition and did not use the objective picture. These channels were based on images and the Internet, which may be due to the difficulty of filming the event, which was carried out entirely within the Saudi consulate in Turkey.

\section{Adherence to Neutrality}

Al-Jazeera and Al-Arabiya did not adhere to neutrality, each relying on specific sources and analysts whose views correspond to the political orientations and affiliation of the channel, as well as adopting a monotonous, nervous or biased view of the event.

While the Nile News Channel committed to neutrality for not relying on sources from any direction, while only reporting the news agencies in response to their sources. 


\section{Features of Positive Coverage of the Event}

The three channels were keen to follow the event and its developments first and to present all the developments over the twenty-one days is the duration of the analysis.

Al Jazeera also presented a variety of media formats, including analytical news, report, commentary and documentary films, as well as the treatment that explains and analyzes the different aspects of the event, presenting different views of the event. As well as the neutrality of the Egyptian channel "Nile News", which was interested in the presentation of information and developments without entering the reasons or offer specific views.

\section{Features of Negative Coverage of the Event}

The coverage was characterized by spontaneity and improvisation, in addition to being superficial and sophisticated, which did not present all the facts to Al-Arabiya and Nile news channels.

While the coverage of Al-Jazeera was characterized by personalization and the release of charges and judgments and the use of resources objectively and the confusion of speculation and information and conclusions even before the completion of investigations and in general characterized the coverage of being completely biased.

As well as the lack of coverage of the Nile News for analysis and interpretation and not link events in their political and social context.

The results of the study are in line with the study of "Eman Mohamed Mohamed 2016", which, through analysis of the content, resulted in a low level of media performance of the content provided by Al Jazeera and Nile News.

The study also confirmed the absence of the three channels (Al-Arabiya - Al Jazeera - Nile News) for professional and ethical media performance standards.

Media Approaching Frameworks for the Case of the Saudi Journalist Khashoggi among the Arab News Channels

(El Arabia - Al-Jazeera -Nile News)

\section{First: Method of Approaching}

Al-Arabiya followed the method of defense and supported Saudi Arabia in its position, which was based on the denial of any connection to the disappearance of the Saudi journalist. Then the method developed with the development of events and the announcement of Turkey's killing of the Saudi journalist inside the Saudi consulate to investigate and demand disclosure of the causes of disappearance. While Qatar's Al-Jazeera channel used to criticize Saudi Arabia, charge and incite international public opinion against the Saudi crown prince.

While the Nile News Channel followed the method of monitoring the facts and follow the developments of information events, and can be explained the difference in the approach to the different policy and political directions of all previous channels and the countries to which they belong.

\section{Second: The Active Forces of the Event in the Media Approaching the Channels under Study}

Al-Arabiya channel focused on Turkey and the United States as an active force in the event and tried to link the negotiations to liberate the US priest held in Turkey for espionage. Al-Jazeera focused on Saudi Arabia, specifically on the 
Saudi crown prince as an active actor in the event, with the charge that he was directed to him of killing the Saudi journalist without concrete evidence.

While the treatment of the Egyptian channel did not show any effective force, where the treatment was characterized by extreme surface and turned into a mere narrative of the event.

\section{Third: Media Frameworks used in the Media Approaching the Disappearance of the Saudi Journalist in the Three Channels}

Al-Jazeera's treatment of the event came within the framework of the conflict between the Saudi Crown Prince and his opponents and the policies of Saudi Arabia. The event was also described as a social responsibility. It blamed the disappearance of the Saudi journalist at the beginning of the event and the responsibility of his killing the Saudi Crown Prince by charging him with responsibility for the journalist's disappearance And guidance within the consulate in Istanbul.

It also dealt with the event in a legal framework and demanding the legal punishment of those whom it described as the perpetrators of the murder of the journalist.

While the Al-Arabiya channel focused on the political framework and filmed the event in the context of the political conflict between Turkey and the United States of America because of the arrest of the American pastor accused of espionage.

While the Nile channel for Egyptian news broadcast the event in the context of general issues that did not receive sufficient attention either in the news story or in the interpretation and analysis of the news.

\section{Fourth: Attraction used in the Presentation of the Event in the Three Channels of Study}

Al-Arabiya channel used in most of its news the emotional attractions based on the use of slogans, symbols, repetition, generalization, and bias in defending the position of Saudi Arabia. While Al-Jazeera used all the logical surges and intimidations, wherein the use of logical gestures to provide evidence and evidence is uncertain, but from the point of view of specialists and analysts. It also focused on the presentation of the reasons for the event that Saudi Arabia eliminated its opponents and used the method of linking causes, results and conclusions through political analysts. It also presented two points of view, although it was clear that it was biased in presenting views supporting its opposition policy to Saudi Arabia. Threats of intimidation were also used by portraying the gravity of the event and taking responsibility for the Saudi consul in Turkey. It also used the threat method and the use of the words that indicate the finger pointing to the Crown Prince of Saudi Arabia, while the Nile News Channel committed to logical reasoning by monitoring the current events and developments of the event.

\section{Factors Affecting Media Approaching in the Three Channels of Study}

It is noticed through follow-up and analysis that the factors influencing the information processors were as follows:

- Policy of the channels: where it comes at the forefront of the factors of influence where we find that the editorial policy and broadcasting of satellite channels interferes with the heads of newsletters deletion and addition may have an impact on the credibility of the media, for example helped the policy of Al Jazeera to adopt the policy of coloring and bias in its coverage of the disappearance of the Saudi journalist. In addition to the adoption of the channel to a unilateral view opposed to the policy of the Saudi government. One of the most important influences 
of the channel policy is the selection of sources and guests whose views correspond to the channel's policy and vision.

- The ownership pattern impacted on the channel's policy as followed Saudi Arabia channel the political line of the Kingdom of Saudi Arabia and the Nile channel committed to news standards of professional and ethical balanced in the event handling while noting the violation of Al-Jazeera professional standards and ethics, including the style of inflaming emotions and excitement and urged the international public opinion against the policy of the Kingdom Saudi Arab

- The nature of the event itself has greatly influenced the standards and frameworks of media approaches. Many studies concluded that the nature of the event itself affects the professional practices of the media. The media may resort to adopting one viewpoint, mostly the official viewpoint (Al-Arabiya channel). The magnitude of the event may affect the manner in which the media is covered by the subject, as well as the location of the event that took place inside the Saudi consulate in Istanbul has also affected on the way of supervision that holds the Saudi consul in Turkey responsibility (Al-Jazeera).

\section{Other Factors Affected the Coverage of this Event Includes}

Ideology, political affiliation, and state policy: many studies have found that the ideology and political affiliation of the media has a great impact on the presentation of the event. Where it became clear that the media attention to any subject is employed to serve the ideology and a particular physical or political perspective. This was clearly reflected in the governmental parties that supported and supported Saudi Arabia's position. It also explained the reflection of the political agenda of the countries on the media coverage of their media (Al-Jazeera), where the policy of opposition and conflict was reflected by the State of Qatar to the Kingdom of Saudi Arabia. While the Egyptian Nile Channel committed itself to neutrality and parallelism in accordance with the Egyptian foreign policy of a balanced position.

\section{Approaching Frameworks of the Disappearance of Jamal Khashoggi in the Three News Satellites under Study}

Table 1

\begin{tabular}{|c|c|c|c|}
\hline Standards & Al Arabiya & Al Jazeera & Nile News \\
\hline $\begin{array}{l}\text { Treatment } \\
\text { orientation }\end{array}$ & $\begin{array}{l}\text { A supporter of Saudi } \\
\text { Arabia's position }\end{array}$ & Opposes to Saudi Arabia's stance & Neutral \\
\hline Treatment method & $\begin{array}{l}\text { Narrative method } \\
\text { using information }\end{array}$ & $\begin{array}{l}\text { Display method using information, } \\
\text { opinion and other opinions. } \\
\text { The arguments method in the form of } \\
\text { evidence of Khashoggi's death }\end{array}$ & $\begin{array}{l}\text { The display method } \\
\text { uses the information } \\
\text { only and follows the } \\
\text { evolution of events. }\end{array}$ \\
\hline Place of treatment & $\begin{array}{l}- \\
\text { Consulate in Turkey } \\
-\quad \quad \text { Kingdom of } \\
\text { Saudi Arabia }\end{array}$ & $\begin{array}{ll}- & \text { Turkey } \\
- & \text { Saudi Consulate in Turkey } \\
- & \text { Khashoggi residence in the } \\
\text { United States of America }\end{array}$ & $\begin{array}{l}\text { Saudi Consulate in } \\
\text { Turkey }\end{array}$ \\
\hline Media model used & $\begin{array}{l}\text { News } \\
\text { News reports }\end{array}$ & $\begin{array}{l}\text { News } \\
\text { News reports } \\
\text { Documentaries }\end{array}$ & News \\
\hline $\begin{array}{l}\text { The focus of the } \\
\text { conspiracy in }\end{array}$ & $\begin{array}{l}\text { Focused on the } \\
\text { conspiracy against }\end{array}$ & $\begin{array}{l}\text { Focused on the conspiracy of the Saudi } \\
\text { Crown Prince against Khashoggi for }\end{array}$ & $\begin{array}{l}\text { Did not use the } \\
\text { conspiracy aspect in the }\end{array}$ \\
\hline
\end{tabular}




\begin{tabular}{|l|l|l|l|}
\hline media treatment & $\begin{array}{l}\text { Saudi Arabia from } \\
\text { Turkey and the United } \\
\text { States }\end{array}$ & being an opposition free journalist & media treatment \\
\hline Actors & Saudi Arabia - Turkey & Saudi Arabia - Turkey & Saudi Arabia - Turkey \\
\hline $\begin{array}{l}\text { Address the speech } \\
\text { of the Turkish } \\
\begin{array}{l}\text { President } \\
\text { "Erdogan" after the } \\
\text { incident }\end{array}\end{array}$ & $\begin{array}{l}\text { Only excerpts were } \\
\text { mostly translated in } \\
\text { the wrong way } \\
\text { "Praised the role of the } \\
\text { Saudi consul in } \\
\text { Turkey" }\end{array}$ & $\begin{array}{l}\text { The speech was broadcast by the } \\
\text { Turkish parliament translated into } \\
\text { Arabic "The Saudi consul was doing } \\
\text { very badly" }\end{array}$ & $\begin{array}{l}\text { Referring to some } \\
\text { points mentioned by the } \\
\text { Turkish president. }\end{array}$ \\
\hline
\end{tabular}

\section{CONCLUSIONS}

It is noted through the previous presentation that the Arab satellite news channels did not adhere to the news treatment frameworks. There was no clear form of news media coverage according to the framework theory, where the media treatment of the channels under study showed clear bias and misleading information represented in the lack of information, inaccuracy and deliberately stir up public opinion. In addition, the treatment in most of them did not adhere to neutrality (Al-Jazeera) nor transparency (Al-Arabiya) nor analysis or interpretation (Nile News Channel).

The media treatment, in general, showed some of the negatives that occurred in the Arab satellite channels, which led to misleading the receiver whether the limited information provided, inaccuracy, bias, exaggeration or underestimation of the event. It emerged from the negative coverage of the media inaccuracies in the presentation of the event and the uncertainty of the validity of the data ((Al Arabiya - Al Jazeera).The Nile News Channel also lacked the background of the event or an explanation or analysis of the event in general. The imbalance and professionalism also appeared clearly in the treatment of Al-Jazeera for the event, where the channel formed a point of view in accusing Saudi Arabia and highlighted the visions that support its orientations. All channels, without exception, lacked comprehensive treatment of events where the event dealt superficially and focused on the event (Al Arabiya) and the actors more focused on the background of the event (Al Jazeera). There was also a lack of analytical and interpretive coverage and insufficient information (Al Arabiya - Nile News). As well as the provision of undocumented information (Al-Jazeera) and sometimes conflicting (Al-Arabiya). It also shows the use of personal images of the Saudi journalist, often at the expense of objective images that give meaning and depth to the event.

Finally, the analysis concluded that the absolute objectivity of satellite news channels does not exist while the news is influenced by the political affiliation and ownership of the channel according to the policy of the state to which the channel belongs. The channel also changes and the news treatment of events according to the nature of the event itself.

Eventually, we can confirm that the speed of news transfer comes at the expense of accuracy and there is no objectivity in the Arab satellite channels where the color and modify and distort information according to policy media in accordance with the ideology and policies of the state to which the channel belongs. Therefore, the Arab Media ministers must adopt the law of information circulation, which helps the credibility of media exchange and exposure through documented information so as not to fall Arab recipient as a victim of disinformation and lack of information.

\section{REFERENCES}

1. Chritian Baden \& Keren Tenenboim Weinblatl (2018) "The search of common ground in conflict news: comparing the coverage of six current conflicts in domestic and international media over time. In media war \& conflict available atwww. sagepubjournal. gate of search 215/10/2018 
2. MD. Sazzad Hossaim (2018) "Social media \& terrorism, treats and challenges to the modem era "south Asian survey vol. 22, 2, p. p $136-155$.

3. Suzan El Kalliny,(2017)"Framing-of-media-coverage-of-the-palestinian-israeli-conflict-in-cnn-and-foxnews(IJELS) journal Nol-2, Issue-4, July - August 2017)

4. Eman Abdul Rahim Al-Sharqawi (2014) "The Dialectical relationship between media and terrorist practices "Applied knowledge on social networks" Scientific Conference, The role of Arab media in addressing the Terrorism phenomenon "Naif University for Security Sciences, Riyadh 16-18 / 12/2014.

5. Malisuwan, S. Design of Ground Station Smart Antenna System for Multimedia Communications in Small Drone Applications.

6. Sam R. Bell, K, Chad day \& other(2014) "The role of external \& internal transparency in terrorism attacks" political research quarterly, March 21, p. p 603-6014.

7. Suzan El Kalliny, (2014) "Media Criticism" [Cairo: Dar Al-Nahdha Al Arabiya]. 